\title{
DIGITAL ANALYSIS WITH 3D SCANNING AND THREE-DIMENSIONAL MODELLING OF THE MAIN CHURCH OF ST. MARY - THE OLD CATHEDRAL, CARTAGENA (REGION OF MURCIA, SPAIN)
}

\author{
P. E. Collado-Espejo ${ }^{1, *}$, J. García-León ${ }^{1}$, F. J. Jiménez-González ${ }^{1}$, C. M. Sánchez-Yepes ${ }^{1}$ \\ ${ }^{1}$ Polytechnic University of Cartagena, Spain - (pedroe.collado, josefina.leon)@upct.es, (franciscoj.jimenezgonzalez, \\ carmen.san.yepes)@gmail.com
}

Commission II - WG II/8

KEY WORDS: Cathedral, Cartagena, 3D Scanning, Digital Analysis

\begin{abstract}
:
The former Church of St. Mary, known as the Old Cathedral, in Cartagena (Region of Murcia, Spain), is a construction from the beginning of the 13th century, but it was transformed in the 16th century and rebuilt at the beginning of the 20th century. The bombings occurring during the Spanish Civil War caused the partial collapse of the building and the state of ruin that it currently presents. It is protected as a PCI with-the category of monument. A Master Plan is currently being developed that should lead to the recovery of the building. The "Thermal Analysis and Geomatics (TAG)" Research Group of the Polytechnic University of Cartagena has collaborated in the drafting of the Master Plan with a planimetric survey and graphic analysis of the entire building. For this purpose, digital terrestrial photogrammetry techniques and a 3D laser scanner compatible with classical topography have been used, in order to obtain an accurate three-dimensional model. All this graphic information has been contrasted with the historical, typological, material and constructive information currently available about the building, which has facilitated the making of an exhaustive three-dimensional analysis that permits us to know this ancient Cathedral in depth. This paper will describe the work methodology followed, the technical means used and the results achieved, which have been incorporated into the Master Plan that is being prepared. Undoubtedly, the digital analysis has helped to obtain a better general understanding of the building and to be able to propose a correct formal, structural and material recomposition.
\end{abstract}

\section{INTRODUCTION}

The old Cathedral of Santa María or the Assumption of Our Lady, in Cartagena (Region of Murcia, Spain), also called the "Old Cathedral", "Ancient Cathedral", "Church of Santa Maria la Vieja" or "Main Church of Santa María ", is a unique building, with great patrimonial, symbolic and cultural value, as well as being a reference in the historical evolution of the city of Cartagena from the fourteenth century to the present day. It is a protected construction as a Property of Cultural Interest (hereinafter PCI, with the category of monument, included in the Special Plan for the Management and Protection of the Historic District of Cartagena with Grade 1 protection and located within the protection area of the PERI of the Roman Theatre (Decree 234/2018). In addition, this property is included in the National Plan of Cathedrals, drawn up by the Ministry of Culture, so its full recovery is a goal worth achieving during the upcoming years. However, the different events that this building has endured, especially from the end of the 19th century until the middle of the 20th century, have given rise to the general state of ruin in which it is found today (Figure 1).

In recent years, the Diocese of Cartagena, as the owner of the property, and the Ministry of Culture of the Region of Murcia have financed different interventions. These actions have allowed the analysis of the building in different ways; materially, constructively and architecturally. Furthermore, it has been possible to acquire more accurate knowledge about the state of conservation of the structures and patrimonial elements that are conserved. During 1983 and 1986, two important archaeological excavations were carried out. And in 2009, the Polytechnic University of Cartagena (hereinafter UPCT) made an initial planimetric and documentary survey (Collado, Martínez, 2009), with precision devices, property of the Department of Architecture and Building Technology, which was completed with a constructive analysis and a study of the pathologies present in the monument.

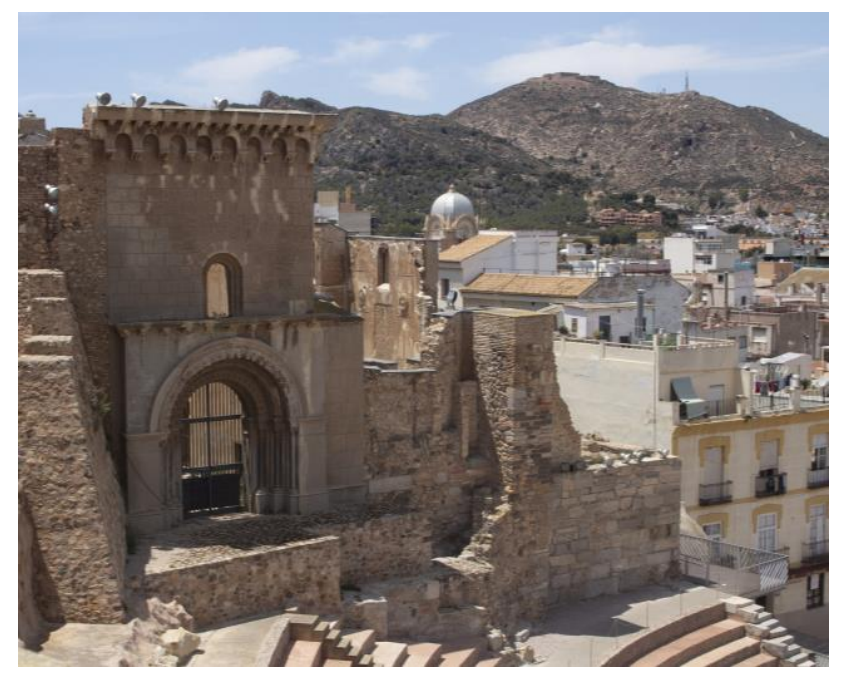

Figure 1. General view of the east facade of the Main Church of St. Mary - the Old Cathedral in Cartagena

\footnotetext{
* Corresponding author
} 
This UPCT study facilitated the restauration works that took place between 2011 and 2012, which consisted of a general cleaning and the consolidation of the walls of the temple. More recently, the restoration of the Cristo del Socorro Chapel was carried out. Taking these recent actions into account, the Bishopric has decided to open the building for scheduled and guided visits, thus incorporating this monument into the wide cultural and touristic offering of the city. However, the overall image of construction debris remains.

Fortunately, the Diocese of Cartagena has proposed the restoration and integral conservation of the monument. With this objective, and as a previous step, the institution has commissioned the preparation of a Master Plan (funded by the Ministry of Culture). Lavila Arquitectos S.L.P., a company run by the architect D. Juan de Dios de la Hoz Martínez, who is a specialist in heritage restoration, has overseen the latest interventions in the building. The Master Plan (according to Decree 234/2018) must establish the general and particular conditions for the conservation and enhancement of the PCI and its environment. In addition, it should be configured as a tool that determines the constituent values of the building and serves as a basis for planning future actions from the perspective of preserving the authenticity of the monument.

On the other hand, a historical building (and especially a monument), should be understood as a "document"; as the not always homogeneous result of different construction processes (additions, partial demolitions, use of different construction materials and systems ...), which require the widest possible knowledge of the building in order to face any intervention (cleaning, consolidation of structures, restoration, conservation ...), with guarantees of success. That is, the drafting of a Master Plan and its future application on a monument requires exhaustive investigation, documentation and analysis of the building and its protective environment (De la Hoz, 2006, p. 366). Thus, the knowledge of the building "means that any intervention proposed in it does not irreversibly manipulate it, but rather, with this exhaustive prior documentation, the support and study of several specialists and the reading and interpretation of the historical-artistic-constructive languages, the condition of the historical document of the building itself is fully achieved (...) and we can only evaluate in detail the various problems if we have precision planimetric documentation "(De la Hoz, 2006, p. 373).

With the experience of the study carried out in 2009 by the UPCT and in which the architect Juan de Dios de la Hoz (supervising the work as the architect hired by the Bishopric) also participated, Lavila Arquitectos SLP subcontracted the "Scanning and drafting of planimetric documentation in Cad format the old Church of Santa María La Mayor/ the Old Cathedral of Cartagena (Region of Murcia)" (Collado, García, 2019) to the Thermal Analysis and Geomatics Research Group (TAG), of the UPCT. This text intends to summarise the methodology and the work carried out for the three-dimensional precision survey of the building and present the results obtained, which have been incorporated into the Master Plan.

\section{CASE STUDY}

\subsection{The Old Cathedral and its history}

The old Church of Santa María - the Old Cathedral in Cartagena, is located between Osario Street (south and west façades) and Condesa de Peralta Square (north facade). On the north-western side the slope of Cerro de La Concepción (the highest of the five hills that delimited the city of Cartagena in Punic and Roman times) can be found. From the archaeological excavations carried out, it is known that this building was constructed over Roman remains, including the Roman Theatre itself.

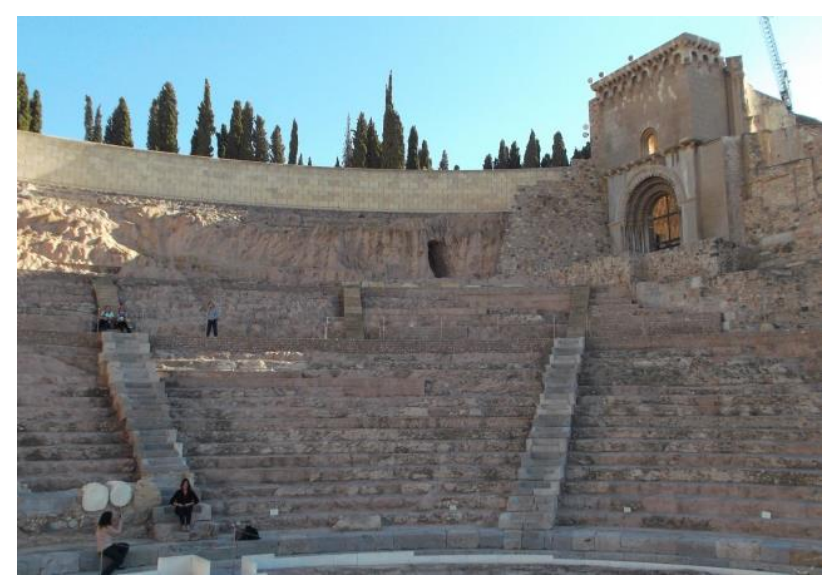

Figure 2. East facade of the Old Cathedral and cavea of the Roman Theater of Cartagena.

The construction of the primitive temple dates from the thirteenth century, as a result of the reconquest of the peninsular southeast by Christian troops. After the conquest of Cartagena, the Concepción castle was built (on the hill of the same name), along with numerous other buildings. The indications of that time seem to conclude that during the thirteenth century, the city erected several buildings on the site of the current building (bell tower among them). Although these constructions could have had religious use, they had no function as a Cathedral at that time (Hernández, 1985). The geographical, economic and social situation of the city did not allow the construction of a proper cathedral. In addition, at the end of the thirteenth century, the headquarters of the Diocese was transferred to Murcia.

It was from the sixteenth century when the Church of Santa María or the Assumption of Our Lady acquired the configuration of a proper Cathedral. At this time the three main naves and a series of adjacent rooms (probably destined for cult chapels) were built, combining the late-Gothic and classicist styles. This century ended with the temple unfinished, awaiting a better economic situation. Several texts of the time speak of architectural elements still to be carried out and difficulties regarding the state of the roof and rainwater filtration (Murcia, 2018). During the following centuries the building was consolidated, with most of the current side chapels in the southern nave constructed and the main façades modified.

Between the end of the nineteenth and the middle of the twentieth centuries, the building underwent a series of transformations that would determine how it arrived to its current state. In the late nineteenth century, the temple suffered, like the rest of the city, the bombing of the Cantonal War (July 1873-January 1874), with both the chapels and much of the west façade being damaged. This damage was repaired through minor restoration.

At the end of the nineteenth century, the building had serious problems in its foundation; the apse and almost the entire north façade sank. Luckily, the stability and economic bonanza of the city (due to the rise of the mining industry) allowed the architect Víctor Beltrí Roqueta (of Catalan origin, trained at the Barcelona school and based in Cartagena), to 
become responsible for the restoration of the temple between 1899 and 1902. However, more than restore it, a new building was built. Beltrí significantly changed both the volume and the architectural style of the temple, completely disfiguring the medieval building. Following the stylistic and architectural approaches of the time; deeply into the principles of the socalled "restoration in style" (theorised by the architect Violletle-Duc), an intervention with a marked neo-Romanesque style outside and a style with neo-gothic aspects throughout the interior was performed (Murcia, 2018). The building was articulated around three naves; one central and two lateral ones, with attached chapels. The entrance consisted of a small door on the east side; although on the west side there was a door of greater dimensions that was considered to be the principal access. It had a bell tower, and in the northern part, an annexed building where the clergymen resided. Unfortunately, this intervention, and therefore the new appearance and the optimal state of conservation of the building, would not last long.

In July 1936, with the beginning of the Spanish Civil War, the temple was assaulted, altars and altarpieces were destroyed and a prison was established inside the building. During 1939 it was bombed, and the roofs and chapels over the northern nave were totally destroyed. From this moment on it was in a state of ruin and was abandoned.

The following decades saw how the state of ruin increased until, in 1988, archaeological remains were discovered in a building mediatorial to the temple, which were identified as part of a great Roman Theatre. Different archaeological excavation campaigns took place from this moment, resulting in bringing the Roman Theatre of Cartagena to the surface. These interventions documented that some parts of the Roman Theatre were under the Old Cathedral (part of the theatre cavea was under the building). This Roman past has been rescued in recent decades, highlighting the construction of the ancient Cathedral on a significant amount of Roman-era buildings (Figure 2). Currently, an archaeological site with the summa cavea and a vomitory can be found in the area occupied by the central and northern naves of the building. In addition, there is a cistern from the time of Emperor Augustus in the basement of the southern nave as well as a Roman mosaic from the second century B.C. in the ancient crypt of the temple, below the northern nave of the monument.

Currently, the old Church of Santa María/ the Old Cathedral in Cartagena, preserves remains of Roman, medieval Islamic and medieval Christian origin, as well as Gothic and Renaissance walls and elements incorporated in the different consolidations, reforms and reconstructions from the eighteenth to the twentieth centuries. Therefore, it can be affirmed that the analysis of this monument generates knowledge about the urban and social evolution of the city and the history of Cartagena itself.

\section{METHODOLOGY}

As has been previously commented, with the drafting of a Master Plan precise and very complete knowledge of the monument is intended, especially that dealing with the traditional materials and techniques with which it was built, as well as its real state of conservation. With this knowledge, the intervention proposals (methodology, techniques, materials, etcetera) can be well founded and their results successful. It is necessary to identify and evaluate the state of conservation of the materials and construction systems (damage, deformation, resistance capacity, etc.). Fortunately, for this analysis we have powerful tools such as precision planimetric modelling with laser scanning technology and digital photogrammetry.

Regarding the work of "Scanning and drafting of planimetric documentation in Cad of the old Church of Santa María La Mayor/ the Old Cathedral of Cartagena (Region of Murcia)", different methods of graphic survey and measurement have been combined, such as classical topography, laser scanning and terrestrial digital photogrammetry. This complementarity of graphic representation methods has been proven in recent years to be the most accurate and effective methodology in the documentation of architectural heritage (García-León et al., 2019) and the most frequently used in the detailed graphic survey of cathedrals (Fassi et al., 2010).

The objective was to obtain a general and detailed graphic definition of the temple. For this purpose, the visits and data collection necessary to proceed with the representation of the three-dimensional model of the entire old cathedral were planned and carried out. The graphic results permit the creation of a highly accurate cross-section or plan of the building, so that the represented element is completely defined.

The methodology used for the volumetric restitution of the entire architectural ensemble has been carried out with the intention of obtaining accurate data according to the different elements to be modelled and the use of each technique depending on the result provided. The terrestrial laser scanner has been used as a global modelling tool through which to obtain a complete point cloud of the building. Digital photogrammetry has been used in singular elements that, due to their specificities, needed a greater level of detail both geometrically and visually. This precision in detail is what allows the analysis of its physical characteristics and the state of conservation (degradation, different damage, etc.) of the architectural elements and their construction materials.

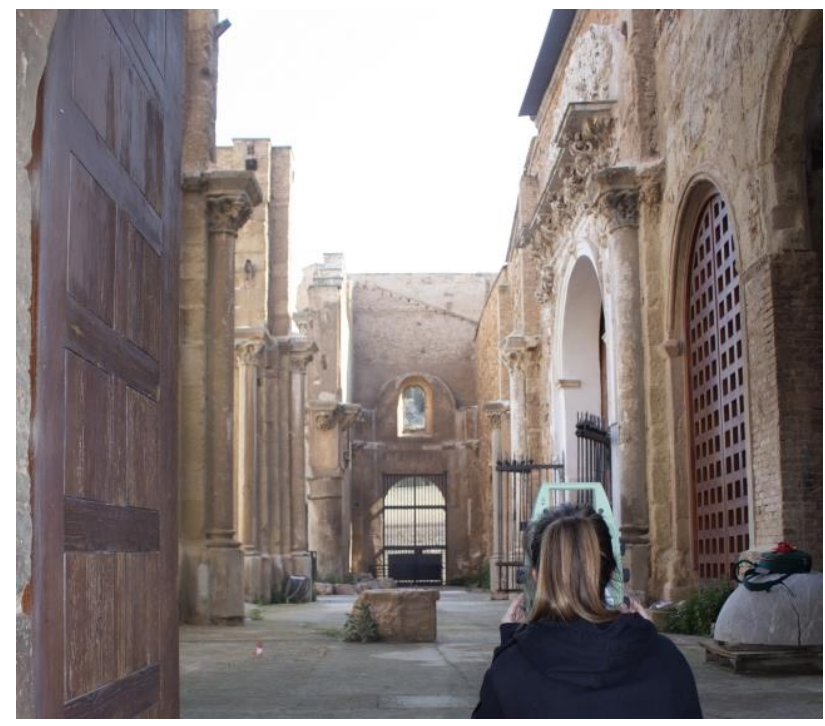

Figure 3. On-site data collection with Leica Nova MS50 multistation inside the building.

The use of different image-capture and graphic representation techniques allows the work to be adapted to the desired objectives. In this way, models with high-resolution digital photogrammetry have been made, as they are detailed models, while the general model of the Cathedral has been optimised to 
adapt it to display on different devices, prioritising the global scale over the particular. Following this criterion, a previous study of the building was carried out that would permit us to confidently engage in such complex data collection.

First, the building was divided into different parts:

- Exterior, Osario Street and Cornisa Park. Laser scanner.

- Exterior, stage and cavea of the Roman Theater. Laser scanner.

- Interior, ships of the temple. Laser scanner.

- Interior, chapels in southern nave. Laser scanner.

- Interior, bell tower. Laser scanner and digital photogrammetry.

- Interior, Roman cistern below ground level. Laser scanner.

- Interior, stairs down to the crypt. Laser scanner.

- Interior, exempt central columns and pillars of central nave. Digital photogrammetry in close detail.

The division of the building into study areas is due to both its architectural complexity and the compatibility of the work to be done with the daily life of the property and its urban environment. It is remarkable that Cartagena's Roman Theatre is visited daily by hundreds of tourists; and the Old Cathedral itself is open to the public, with guided tours four days per month. Therefore, it is essential to plan and coordinate field work with entities such as the Museum of the Roman Theatre of Cartagena, which manages all these cultural visits.

Classic topography is used as a support technique throughout the work. There are two fundamental issues in which this technique participates: the establishment of the bases through a closed polygon (with the same coordinate system in all point clouds), and in the measurement of support and control points (taking at least three points from each of the stations). The ability of the Leica MS50 multi-station to perform this type of topographic operations greatly facilitates this task.

\subsection{Laser scanner work}

The field work was carried out between April and May, 2019, mainly using a laser scanner (Figure 3). The modelling of some detail elements were done with terrestrial digital photogrammetry. The difficulty of the graphic survey of the Old Cathedral of Cartagena lies in the large differences in height and the difficulties posed by the unique spaces of the cathedral complex. The stairs of descent into the crypt and the Roman cistern or "well of San Isidoro", were two of the most complicated volumes to analyse due to their difficult accessibility and the lack of space to station the laser scanner.

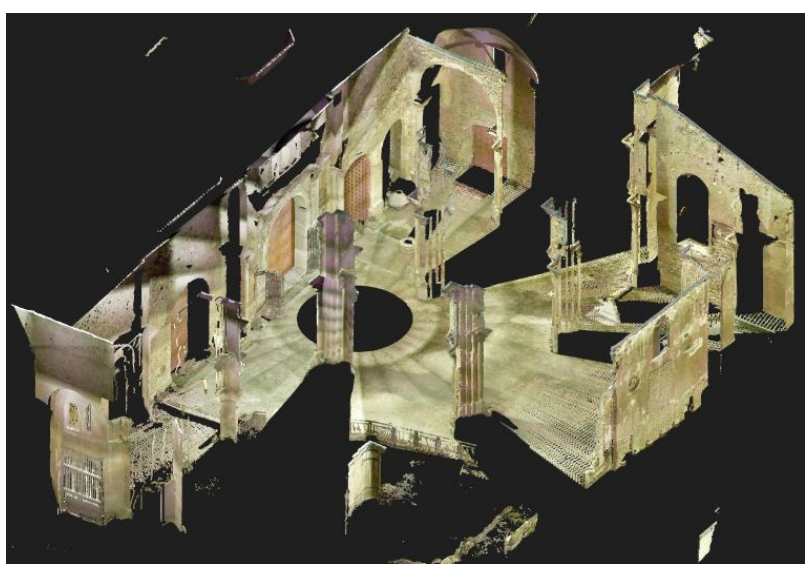

Figure 4. View of the textured point cloud inside the building.
The analysis of the water tank, despite its complexity, was considered fundamental. This cistern originates from the Roman presence in the city; more specifically from the reign of Emperor Augustus. Like other hydraulic constructions in the city, it has a slight slope to the north for decanting into a silt pool, which is totally covered by a barrel vault. The cistern was fully scanned with the laser scanner through a complete vault scan, covering $360^{\circ}$ horizontally, obtaining a total of $2,396,455$ points and 5 control points, which were linked to the rest of the model.

Currently, the stairs of descent into the crypt, built in the restoration overseen by the architect Víctor Beltrí Roqueta, are separated from the rest of the temple and integrated in the route of the Museum of the Roman Theatre. This staircase begins in the northern nave and descends to the pavement, corresponding to two rooms of an ancient Roman domus, discovered in the excavations carried out in 1877 . This separation greatly hinders its integration into the rest of the survey, since there are no visual elements to directly connect it, except for a window on the western façade of the temple. In addition, the limited space available on the stairs was an added difficulty. To capture the whole space of the stairs, three stations were established, with one scan made from each station. Up to four support points were taken in the western window to enable a manual alignment with the support points during cabinet work, and later, an alignment by "Best Fit" was made. Finally, staircase scans were integrated into the rest of the 3D model, referring it to the rest of the spaces and volumes of the monumental building.

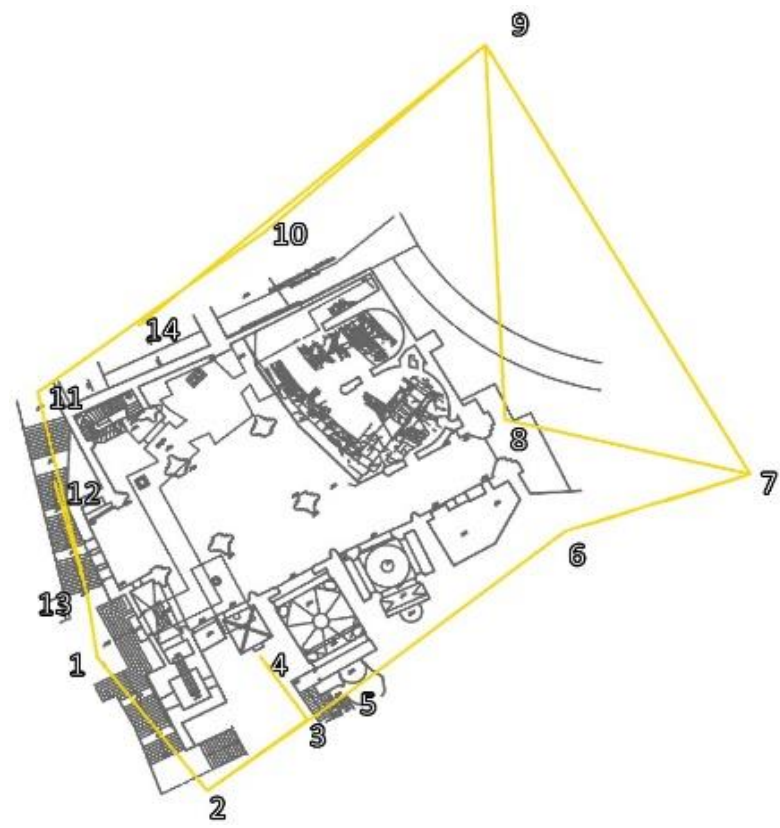

Figure 5. Location map of the 14 stations.

For the on-site data collection, a Leica Nova MS50 multi-station from the Department of Architecture and Technology of the UPCT was used. As previously mentioned, the fieldwork entails special technical difficulties due to the size of the property to be analysed, as well as the large differences in elevation between the spaces to be documented. For this reason, the stations were organised into two interconnecting rings; one totally exterior with 14 stations (Figure 5), linked to another interior one, with 17 stations. Therefore, 31 stations were linked through classic topography. From the different stations, a total of 37 laser scans have been taken, which have allowed the modelling of the volume of the Old Cathedral as a whole. 
Initially, a total of 95 million points were obtained; information that had to be treated and optimised with the Leica Infinity software in order to incorporate them into the digital model. A total of 75 control points was taken from the different stations, distributing them throughout the building to later certify the accuracy of the three-dimensional model obtained.

\subsection{Digital photogrammetry of singular elements}

As a complement to the use of laser scanning for the global scale of the building, terrestrial digital photogrammetry was used to carry out the digital model of the bell tower as well as the exempt central columns in the central nave of the Old Cathedral.

Digital terrestrial photogrammetry offers results comparable in precision to laser scanning, as evidenced by many recent studies (Rodríguez-Navarro, Fantini, 2012). SfM (Structure from Motion) photogrammetric modelling algorithms have resulted in a breakthrough in recent years, becoming a perfect tool for small or medium-sized objects or buildings.

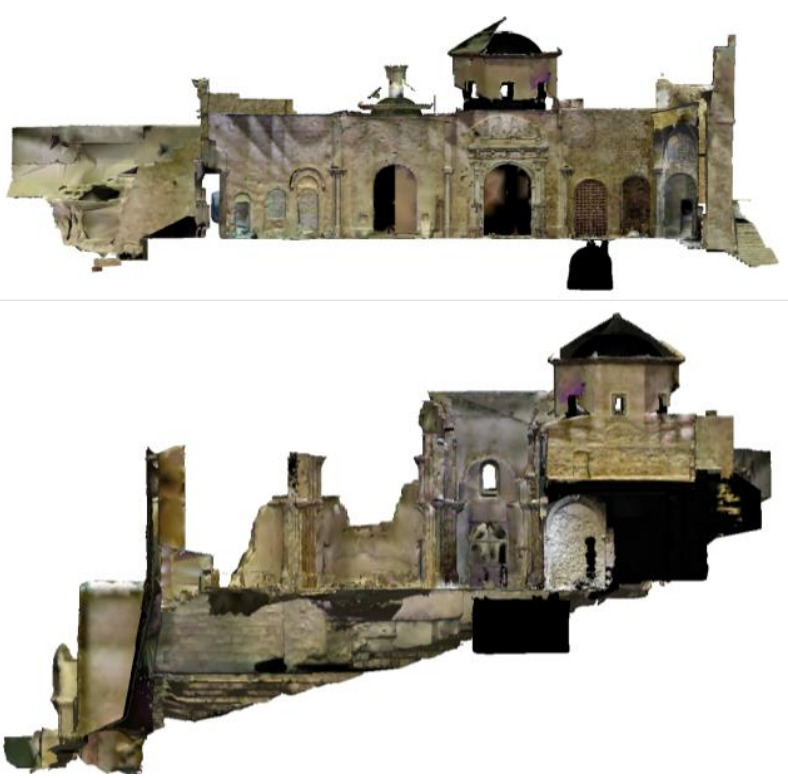

Figure 6. Elevation interior of the building sectioning by the Roman Cistern (above) and by side chapels (below).

In this way, modelling is perfectly possible through the taking of photographs from different points of view covering the entire surface to be restored with sufficient overlap between photographs (over $60 \%$ is recommended). However, modelling the whole building only using photogrammetry would consume a great amount of processing time, and it would be very difficult to manage the resulting model. Consequently, this technique was used only to model specific parts of the buildings, as was mentioned before.

Software based on this technology determines the position in the space of each photograph with respect to the object under study. Subsequently, and in a fully automated way, this technology performs an analysis of homologous points between the different photographs used to obtain a three-dimensional point cloud. This point cloud can later be converted into a three-dimensional mesh based on triangles with a texture generated from the pixel information of the photographs used. The resulting model can be exported to the usual extensions of 3D modelling software, such as .obj or .stl, which allows it to be integrated into the rest of the model generated through laser scanning.
A Canon EOS 700D with rigid tripod and EFS 18-55 $\mathrm{mm} \mathrm{f} / 3.5-$ 5.6 lens has been used to perform the precision graphic survey of the old Church of Santa María. The photographs were generated in .raw format to ensure high file quality as well as to enable correction of the white balance previous to the modelling.

To carry out this work, a focal length equivalent to $50 \mathrm{~mm}$ has been used, opting for an ISO sensitivity of 200, an aperture diaphragm F16 and a shutter speed of 1:20. Likewise, we chose to use natural light in all cases, obtaining colours the most approximate to the real tones possible. In the case of the central columns, shutter speeds of 1/20, an aperture of F16 and ISO sensitivity of 200 have been used.

The restoration of the columns of the central nave of the temple has included a total of 577 photographs, taken from different points of view and forming a circle around each of them, generating a three-dimensional mesh for each of the columns to be modelled (Figure 7)

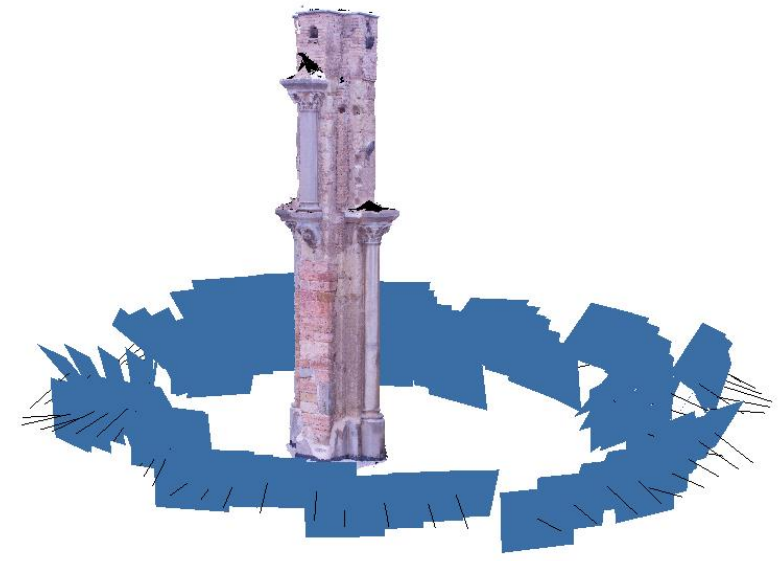

Figure 7. Digital photographic restoration of one of the central columns of the building.

Regarding the optimisation of the textural quality of the images, consideration was given to two important aspects. The first one was that during the days of shooting the photographs, they had to be taken under sufficiently good lighting conditions to not require the use of high levels of ISO sensitivity or cast strong shadows on the object of study. In general, it is advisable to take pictures at those times of the day when the sun is not at a high altitude. Cloudy days are recommended. In this way we not only improve the final result of the texture but also maximise the oriented photographs during processing. However, it is not always feasible to choose the perfect day and time to shoot photographs, so it is possible to take the photos in unsuitable conditions. In this case, digital tools and techniques are available for white and colour correction.

The second aspect to consider for the optimisation of the texture quality of the generated images corresponds to the colour obtained. Photographs taken in different orientations or at different times of day will foreseeably have different intensities of light, angles of incidence or shadow areas, which will affect the surface of the object to be restored. Therefore, it is advisable to use grey balance and colour charts. The neutralisation of this type of irregularity is totally advisable, thus reducing possible large variations in the final result. It must be borne in mind that the final images will be used to accurately identify and measure materials and the presence of pathologies, so neutralising irregularities in the images is essential. 


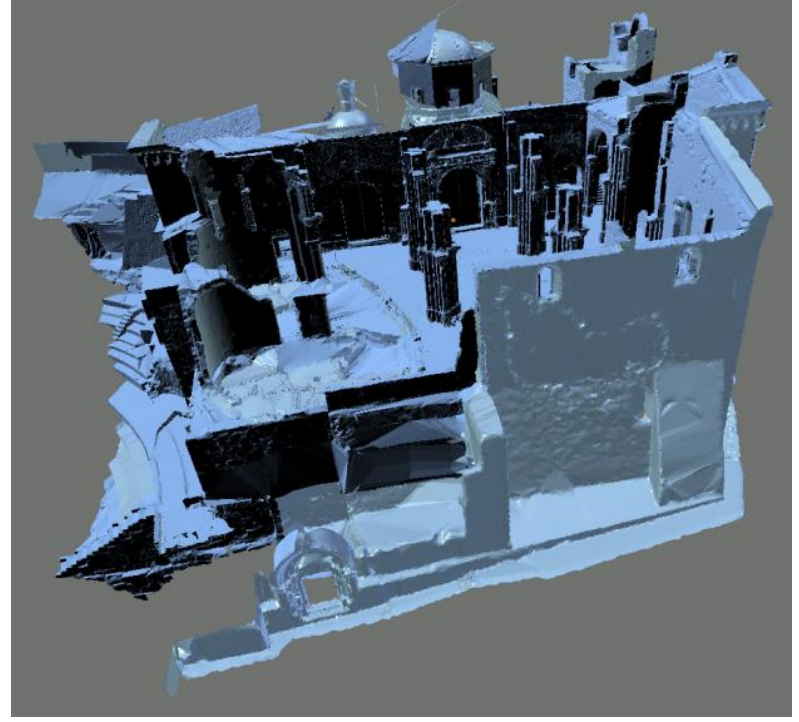

Figure 8. Image of the result of the mesh of points after the optimization and closing of the geometry of the building

To avoid this type of problem, the works were planned by taking the photographs during daylight hours with reduced sunlight, so that both the central columns and the bell tower had the minimum amount of shadows cast and general uniformity throughout their surface. The use of natural light in all the elements (including the interior of the bell tower) was decided to obtain a model as faithful as possible to the natural one. During the data collection, an Xrite ColorChecker colour chart was used to perform the subsequent white balance.

Finally, a total of seven, three-dimensional polygonal meshes were obtained (one for each central column and another for the bell tower), with a texture compensated with camera profiles used in Adobe Lightroom. The result is high quality triangular meshes, textured from high-resolution digital photographs taken in situ. These photogrammetric meshes have been used to perform analyses and diagnoses of the evolution and conservation status of these elements with great constructive and historical wealth, permitting the identification and study of the many historical strata that are superimposed.

\section{CONCLUSIONS}

The old Church of Saint Mary/ the Old Cathedral in Cartagena, is a heritage and cultural reference in the city. Through its study, we are able to discover the historical and social evolution of Cartagena from the fourteenth century to the present. It is a protected building as a PCI with the category of monument, and it is included in the Special Plan for the Management and Protection of the Historic District of Cartagena, in the PERI regarding the Roman Theatre and in the National Plan of Cathedrals of the Ministry of Culture. The building currently retains remains of Roman, medieval Islamic and medieval Christian origin, as well as Gothic and Renaissance walls and elements incorporated throughout the different reforms from the eighteenth to the twentieth centuries. Therefore, a historical building of this importance should not present the general image of ruin and abandonment that, since the bombings it suffered in 1939, seem to have been consolidated.
Since the end of the twentieth century, the Diocese of Cartagena, as the owner of the property, and the Ministry of Culture of the Region of Murcia have financed interventions that have allowed the building to be analysed obtain basic knowledge of the state of conservation of the heritage structures and elements that are still preserved. For example, during 2009, the UPCT made an initial planimetric and documentary survey, which was completed with a constructive and pathological analysis of the monument. This study facilitated the completion of cleaning, consolidation of the walls, and recently, the restoration of the Cristo del Socorro Chapel. With these interventions, the Bishopric has decided to open the building for scheduled and guided tours, incorporating the monument into the city's broad cultural and touristic offering.

In addition, the Diocese of Cartagena has proposed the restoration and integral conservation of the monument. As a previous step, the Diocese has commissioned the preparation of a Master Plan to the architect D. Juan de Dios de La Hoz (through his company Lavila Arquitectos SLP), with the objective of obtaining a document that would determine the constituent values of the PCI and that could serve as a base for the methodology of the intervention and the planning of future actions from the perspective of the preservation of the authenticity of the monument.
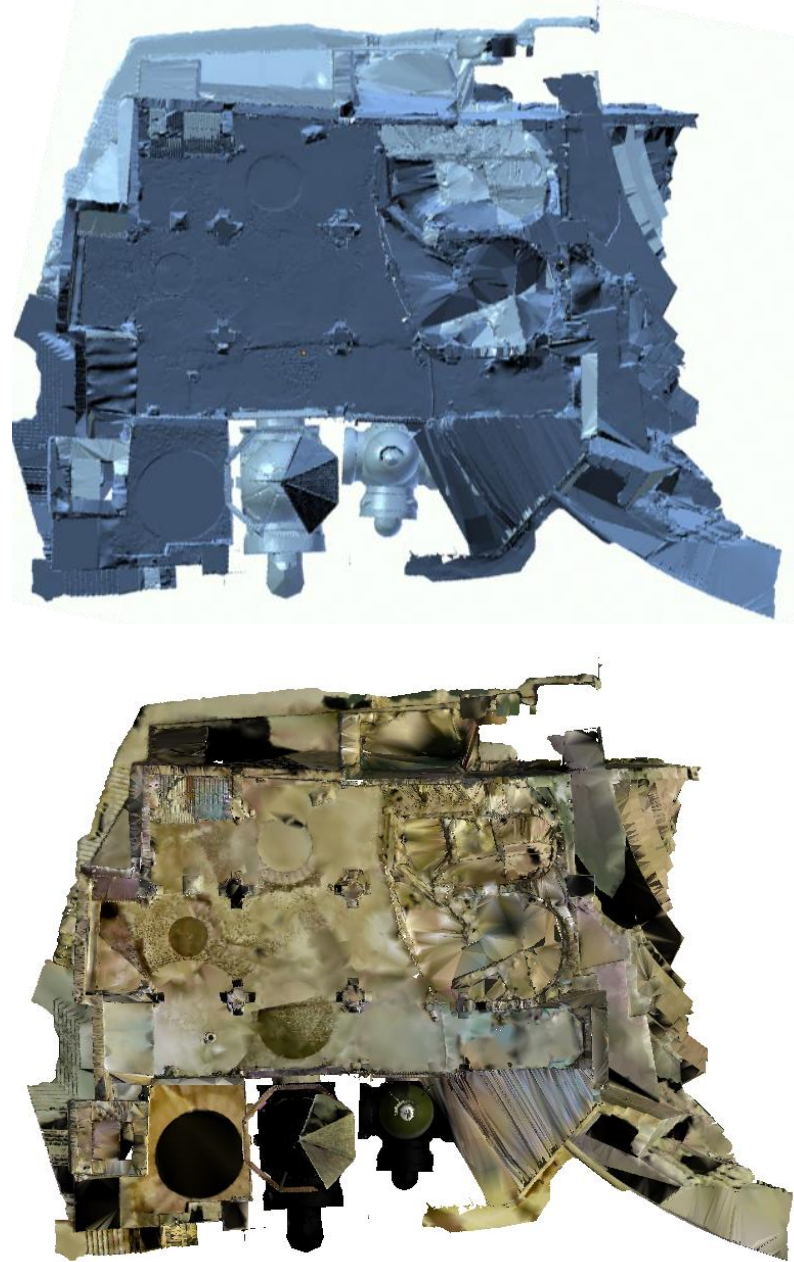

Figure 9. Building plan with the mesh of points without texturing (above) and with the mesh of textured (below). 
On the basis that the various problems that a historic building present can only be evaluated if there is accurate planimetric documentation available, and considering the experience of the collaboration with the study carried out on this building in 2009 , Lavila Arquitectos subcontracted the "Scanning and drafting of planimetric documentation in Cad format of the old Church of Saint Mary the Great/ the Old Cathedral of Cartagena (Region of Murcia)" to the Thermal Analysis and Geomatics Research Group (TAG), of the UPCT.

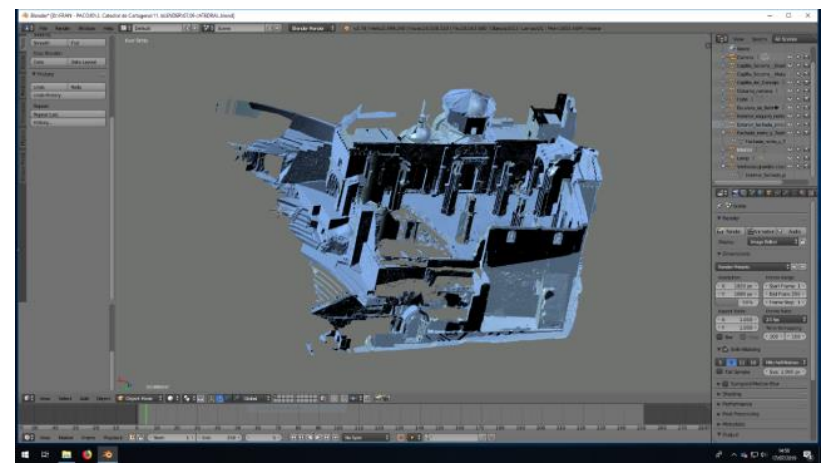

Figure 10. Example of the optimization of the triangular mesh with the use of the Blender program.

The analysis and precise graphic survey of the old Cathedral was a challenge; both for the size and complexity of the cathedral complex and for its relevance. This work is part of the documentation of the Cathedral's Master Plan. Graphic information is essential for the general evaluation of the building, and therefore, as a basis for decision-making in the future integral restoration of the temple. Thus, the heritage value and symbolism of the building has been taken into account during the preparations of the project.

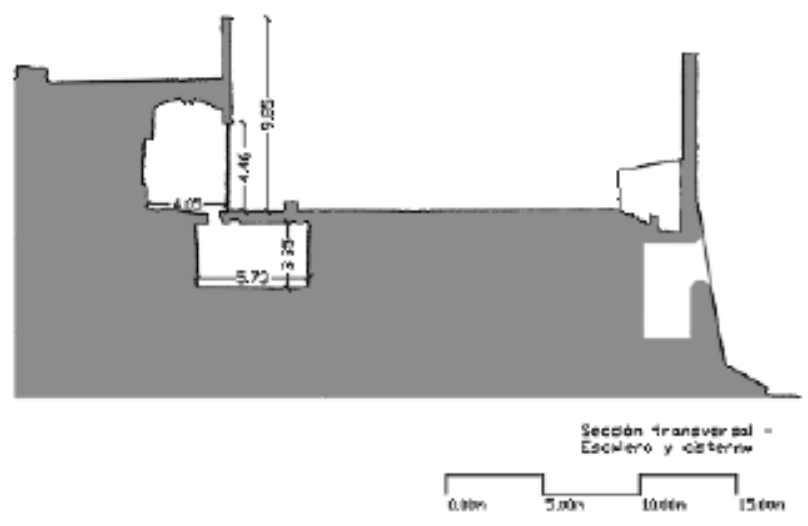

Figure 11. Cross section through the Roman cistern and the staircase made by the architect Victor Beltrí in the early twentieth century.

Powerful tool combinations for graphic survey such as digital terrestrial photogrammetry and laser scanning, together with classic topography, have allowed us to accurately document this tremendously complex building. This monument is more than 2000 years old, with structures and elements that show the large number of restorations and modifications that it has undergone throughout its history, which are a living document of the urban and social evolution of the city.
The graphic survey of the Old Cathedral of Cartagena has presented some difficulties due to the differences in height and the difficulty of accessing some of the spaces of the cathedral complex. The stairs down to the crypt and the Roman cistern were two of the most complicated spaces to analyse. However, the precision graphic survey of these elements was thought to be of great importance, considering the objective of documenting the building as a whole. Therefore, as a result of the investigation carried out, it has been possible to survey elements which had not been properly documented until recently. The integration of the point cloud of the stairs of descent into the crypt and of the Roman cistern within the global model of the Old Cathedral, provide security about the location of these volumes. Precision planimetry has permitted the evaluation of its state of conservation and the prospect of the future restoration of the temple with guarantees.

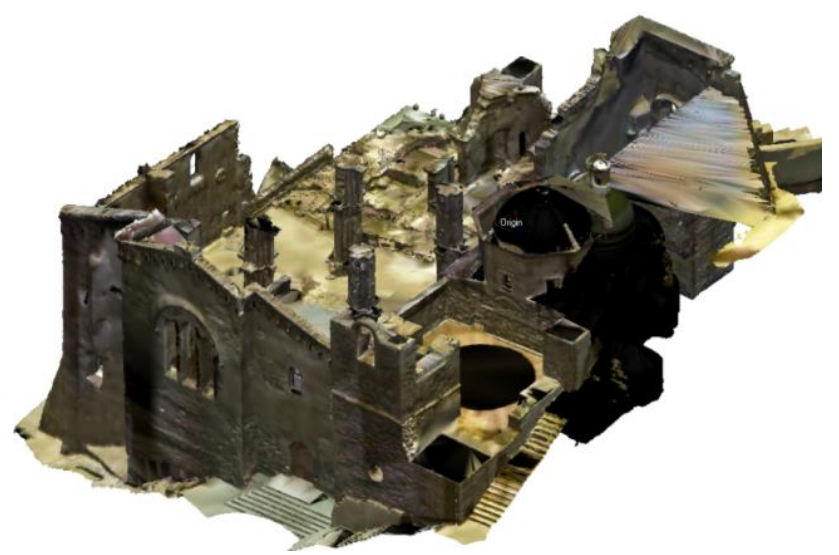

Figure 12. Textured digital bulding model.

Finally, it should be noted that the constructive and graphic analysis carried out has allowed the identification and documentation of the different materials and construction systems of the building, as well as its state of conservation. A vast amount of highly accurate information has been obtained, such as surfaces, wall thicknesses, the exact inclination of structural elements, a detailed map of deterioration and the complete 3D model of the building. Therefore, the digital analysis produced has helped to improve the general understanding of the building and will be incorporated into the Master Plan currently being drafted. It is a guarantee to inform the decision-making of the general and particular conditions for the future integral restoration, conservation and enhancement of the old Church of Saint Mary/ the Old Cathedral, a heritage and cultural reference in Cartagena and the Region of Murcia.

\section{REFERENCES}

Collado Espejo, P. E., García León, J., 2019. Escaneado y redacción de documentación planimétrica en Cad de la antigua Iglesia de Santa María La Mayor - Catedral Vieja de Cartagena (Región de Murcia). Universidad Politécnica de Cartagena, Contrato Ref. 5854-2019-ATE.

Collado Espejo, P. E., Martínez García, J. J., 2009. Taller de Restauración Monumental Cartagena 2009. Levantamiento planimétrico y documental de la Catedral Vieja de Cartagena. XX Jornadas de Patrimonio Cultural de la Región de Murcia. Ediciones Tres Fronteras, pp. 7-19. 
De la Hoz Martínez, J. D., 2006. Aspectos a considerar en la redacción del Plan Director de un monumento. Dos décadas de planes directores en España. XVII Jornadas de Patrimonio Histórico. Consejería de Educación y Cultura de la Región de Murcia, pp. 357-380.

Decreto 234/2018, de 28 de noviembre, por el que se establecen las normas especiales reguladoras de la concesión directa de una subvención al Obispado de la Diócesis de Cartagena, para la redacción del Plan Director para la Restauración de la Iglesia de Santa María la Vieja de Cartagena. (BORM n ${ }^{\circ}$ 277, de 30 de noviembre de 2018).

Fassi, F., Achille, C., Fregonese, L., Monti, C., 2010. Multiple data source for survey and modelling of very complex architecture. International Archives of Photogrammetry, Remote Sensing and Spatial Information Sciences, Vol. XXXVIII,

García-León, J., Collado Espejo, P. E., Jiménez González, F. J., 2019- Negro Tower: Documentation, Conservation and Restoration. Int. Arch. Photogramm. Remote Sens. Spatial Inf. Sci., XLII-2/W15, pp. 489-496, https://doi.org/10.5194/isprsarchives-XLII-2-W15-489-2019.

Hernández Albaladejo, E., 1985. El Templo de Santa María de Gracia de Cartagena: Un Proyecto Inacabado. Imafronte $n^{\circ} 1$, Universidad de Murcia, pp. 87-105.

Murcia Muñoz, A., 2018. La Catedral Vieja de Cartagena, Una visión desde la arqueología. Fundación del Teatro Romano de Cartagena.

Rodríguez-Navarro, P., Fantini, F., 2012. The interpretation of archaeological persistence to generate digital 3D architectural typologies. The case of ksar Tatiouine in the Moroccan High Atlas. Cultural Heritage and New Technologies Workshop 16, November 14-16, 2011 proceedings. Phoibos Verlag, Vienna. pp. 326-335.

Yastikli, N., 2007. Documentation of cultural heritage using digital photogrammetry and laser scanning". Journal Cultural Heritage, vol. $8 n^{\circ} 4$, pp. 432-427.

http://www.sciencedirect.com/science/article/pii/S12962074070 01082 